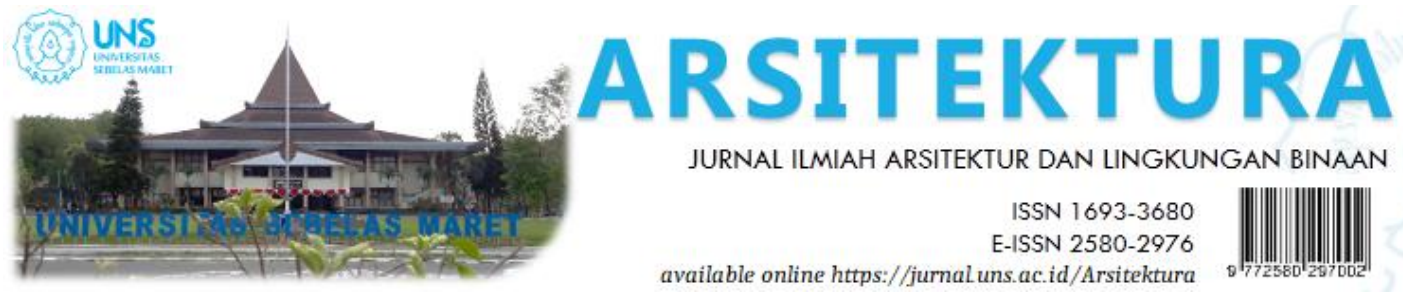

Volume 18 Issue 1 April 2020, pages:43-52

\title{
Identifikasi Aspek Pengembangan Kawasan Konservasi Penyu Pantai Trisik sebagai Wadah Wisata Edukasi Penyu di Kulonprogo
}

\section{Identification of the Development Aspects of Trisik Beach Sea Turtle Conservation Area as a Turtle Education Tourism Object in Kulonprogo}

\author{
Chiquita Darmarani $^{1 *}$, Mohamad Muqoffa ${ }^{2}$, Ummul Mustaqimah $^{3}$ \\ Program Studi Arsitektur, Fakultas Teknik, Universitas Sebelas Maret ${ }^{1 *}$ \\ Email : chiquitadarmarani@student.uns.ac.id \\ Program Studi Arsitektur, Fakultas Teknik, Universitas Sebelas Maret ${ }^{2}$ \\ Program Studi Arsitektur, Fakultas Teknik, Universitas Sebelas Maret ${ }^{3}$
}

DOI: https://doi.org/10.20961/arst.v18i1.34836

Received: October 4, 2019 Revised: March 20,2020 Accepted: March 20,2020 Available online:April 30, 2020

\begin{abstract}
Sea turtle is classified into endangered animal. One of the areas which is designated as sea turtle conservation area in Indonesia is located at Trisik Beach, Kulonprogo. The government's sea turtle conservation effort is supported by the Penyu Abadi Conservation Group, that has been carrying out sea turtle conservation activities since 2004. By the development of this conservation activities, in 2018, Dinas Pariwisata Daerah Istimewa Yogyakarta finally planned a development program for the attractiveness of sea turtle conservation areas on the southern coast of Yogyakarta, including Trisik Beach. One form of developing the attraction of conservation areas is sea turtle educational tourism object. The development of a sea turtle conservation area into a tourist attraction for sea turtle education should not disturb the balance of the natural ecosystem of Trisik Beach sea turtle nesting. Therefore, the problem formulated in this research is what aspects must be fulfilled to realize the recreational sea turtle educational tourism, by paying attention to its main function as a supporter of regional marine conservation activities. The problem solving is done by applying the applied research methods, namely the type of research that aims to provide practical solutions for the problem. This research produced some guidelines that can be implemented in the development of Trisik Beach sea turtle conservation area, to be the basis for future development planning.
\end{abstract}

Keywords: sea turtle conservation, educational tourism, Trisik Beach, recreational design principle, development of regional marine conservation areas principle

\section{PENDAHULUAN}

Penyu merupakan reptil laut yang masuk ke dalam daftar hewan terancam punahError! Reference source not found.. Keberadaannya telah lama terancam, baik dari alam maupun kegiatan manusia Error! Reference source not found.. Pergeseran fungsi lahan, pengelolaan teknik konservasi yang tidak 
memadai, perubahan iklim, pemburuan penyu dan telurnya secara ilegal, serta ancaman predator menjadi faktor-faktor penyebab turunnya populasi penyu Error! Reference source not found. Isu kepunahan penyu tersebut membuat Indonesia yang menjadi habitat 6 dari 7 spesies penyu di dunia, memiliki kewajiban untuk ikut berperan menjaga kelestarian penyu laut (Direktorat Konservasi dan Taman Nasional Laut, 2009). Salah satu bentuk menyelamatkan penyu laut di Indonesia adalah dengan meningkatkan kesadaran masyarakat pada upaya perlindungan penyu Error! Reference source not found.. Peningkatan kesadaran masyarakat pada upaya perlindungan penyu dilakukan dengan memberikan edukasi seputar penyu kepada masyarakat.

Dusun Trisik, Desa Banaran, Kabupaten Kulonprogo, merupakan salah satu daerah yang telah ditetapkan sebagai kawasan konservasi penyu di pesisir pantai selatan Yogyakarta (Pemerintah Daerah Kulonprogo, 2012). Upaya konservasi penyu Pemerintah Kulonprogo, didukung oleh adanya Kelompok Konservasi Penyu Abadi di Pantai Trisik Error! Reference source not found.. Kegiatan konservasi oleh Kelompok Konservasi Penyu Abadi telah dilakukan sejak tahun 2004Error! Reference source not found.. Dalam perkembangan kegiatan konservasi tersebut, Dinas Pariwisata Daerah Istimewa Yogyakarta pun telah merencanakan untuk melakukan pengembangan daya tarik kawasan konservasi penyu di pantai selatan Daerah Istimewa Yogyakarta, termasuk Pantai Trisik (Dinas Pariwisata Daerah Istimewa Yogyakarta, 2018). Lokasi kawasan pengembangan konservasi penyu Pantai Trisik (Gambar 1)

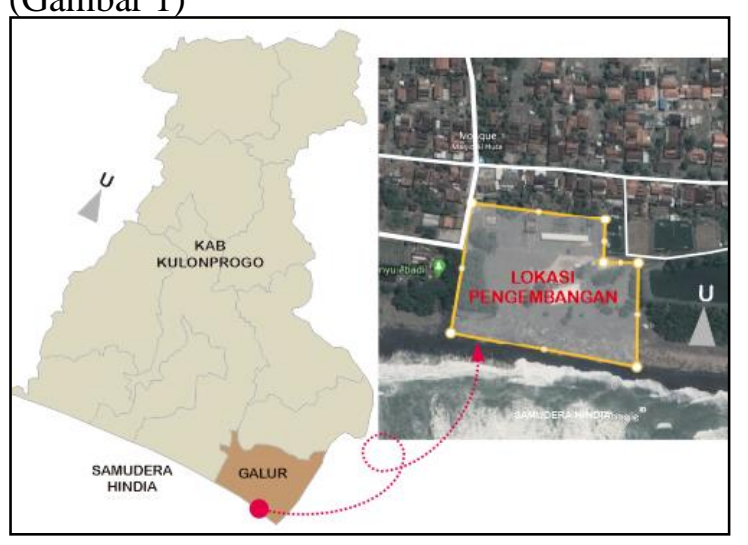

Gambar 1. Lokasi Pengembangan Kawasan Konservasi Penyu Pantai Trisik

Secara teknis, kegiatan konservasi yang dilakukan meliputi pemantauan penyu bertelur, penetasan telur semi alami, pembesaran tukik, dan pelepasan tukik. Namun, pusat konservasi penyu diizinkan untuk memiliki kepentingan khusus seperti pendidikan, penelitian, dan wisata, sehingga beberapa tukik hasil penetasan semi alami dapat dibesarkan pada pusat konservasi (Direktorat Konservasi dan Taman Nasional Laut, 2009). Penyu yang bertelur di Pantai Trisik adalah jenis penyu sisik (lihat Gambar 2a), penyu lekang (lihat Gambar 2b), dan penyu hijau (Lihat Gambar 2c). Masing-masing jenis penyu tersebut memliki karakteristik yang akan mempengaruhi proses identifikasi aspek pengembangan kawasan konservasi penyu Pantai Trisik sebagai wadah wisata edukasi penyu. Karakteristik masing-masing jenis penyu Pantai Trisik dapat dilihat pada Tabel 1.

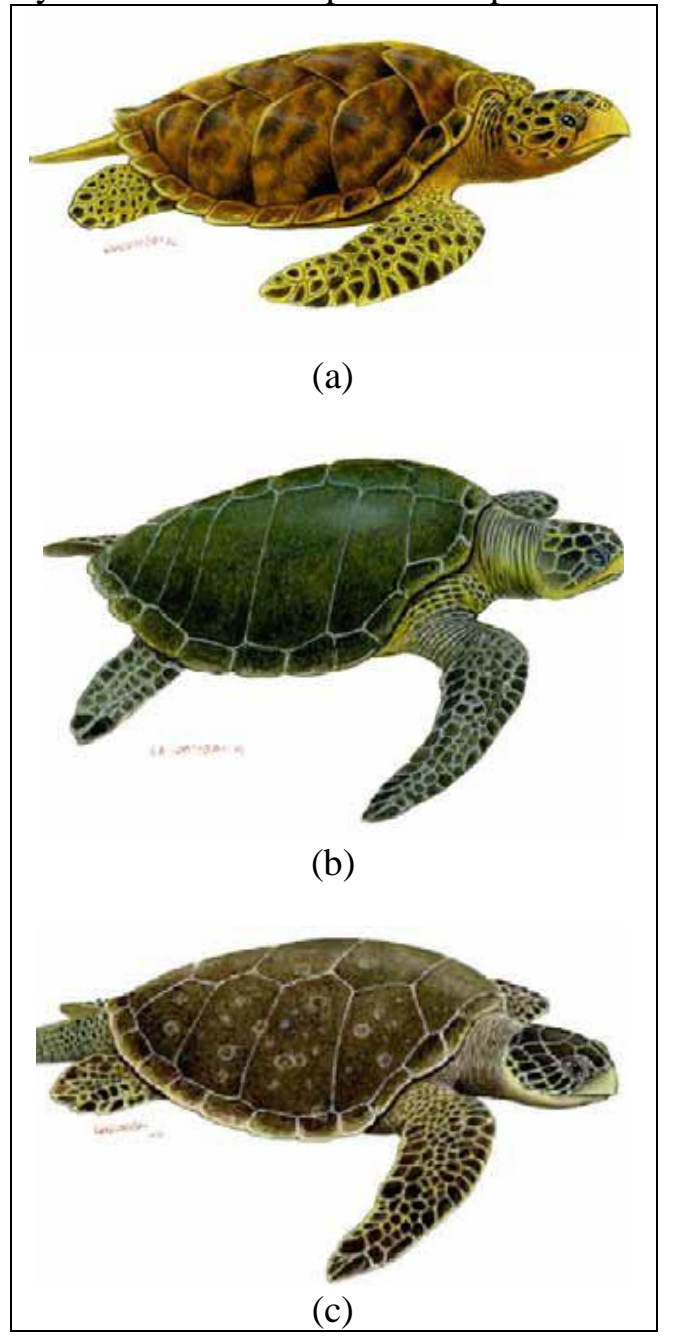


Gambar 2. Jenis-jenis Penyu Pantai Trisik Sumber: Direktorat Konservasi dan Taman Nasional Laut, 2009

Tabel 1. Karakteristik Penyu Pantai Trisik

\begin{tabular}{|c|c|c|}
\hline Ciri-Ciri & Makanan & $\begin{array}{c}\text { Jumlah } \\
\text { Telur }\end{array}$ \\
\hline \multicolumn{3}{|l|}{ Penyu Sisik } \\
\hline $\begin{array}{l}\text { - Panjang lengkung } \\
\text { karapas berkisar } 90 \\
\mathrm{~cm} \\
\text { - Memiliki muka } \\
\text { yang kecil dan } \\
\text { rahang seperti } \\
\text { paruh rajawali } \\
\text { - Terdapat } 4 \text { pasang } \\
\text { lempengan pada } \\
\text { karapas } \\
\end{array}$ & $\begin{array}{l}\text { Termasuk } \\
\text { karnivora } \\
\text { (memakan } \\
\text { karang } \\
\text { lunak, cumi, } \\
\text { udang) }\end{array}$ & $\begin{array}{l}130 \\
\text { butir } \\
\text { tiap } \\
\text { kali } \\
\text { bertelur }\end{array}$ \\
\hline \multicolumn{3}{|l|}{ Penyu Lekang } \\
\hline $\begin{array}{l}\text { - Jenis penyu yang } \\
\text { berukuran paling } \\
\text { kecil } \\
\text { - Panjang lengkung } \\
\text { karapas berkisar } 70 \\
\text { cm } \\
\text { - Karapasnya } \\
\text { berwarna hijau } \\
\text { tetara } \\
\text { - Terdapat } 6 \text { atau } \\
\text { lebih pasang } \\
\text { lempeng karapas }\end{array}$ & $\begin{array}{l}\text { Termasuk } \\
\text { omnivora } \\
\text { (memakan } \\
\text { kepiting, } \\
\text { udang, } \\
\text { lobster, } \\
\text { lamun, alga, } \\
\text { ikan kecil) }\end{array}$ & $\begin{array}{l}110 \\
\text { butir } \\
\text { tiap } \\
\text { kali } \\
\text { bertelur }\end{array}$ \\
\hline \multicolumn{3}{|l|}{ Penyu Hijau } \\
\hline $\begin{array}{l}\text { - } \text { Merupakan penyu } \\
\text { terbesar kedua } \\
\text { - Memiliki } 4 \text { pasang } \\
\text { lempeng karapas } \\
\text { - Jaringan lemak } \\
\text { pada siripnya } \\
\text { berwarna hijau } \\
\text { - Bentuk karapas } \\
\text { menyerupai bentuk } \\
\text { hati }\end{array}$ & $\begin{array}{l}\text { Termasuk } \\
\text { herbivora } \\
\text { (memakan } \\
\text { lamun dan } \\
\text { alga) }\end{array}$ & $\begin{array}{l}115 \\
\text { butir } \\
\text { tiap } \\
\text { kali } \\
\text { bertelur }\end{array}$ \\
\hline
\end{tabular}

Sumber: WWF Indonesia, 2011

Penyu betina akan naik ke pantai saat masa peneluran tiba. Setiap jenis penyu memiliki waktu peneluran yang berbeda satu sama lain. Penyu hijau memiliki waktu peneluran pada pukul 21.00 hingga pukul 02.00. Penyu lekang memiliki waktu peneluran pada pukul 20.00 hingga pukul 00.00. Penyu sisik memiliki waktu peneluran yang tidak pasti, yaitu kadang malam hari atau pun siang hari (Direktorat Konservasi dan Taman Nasional Laut, 2009).

Kegiatan konservasi dimulai melalui kegiatan pemantauan penyu bertelur. Kegiatan pemantauan penyu bertelur harus dilakukan dengan hati-hati, karena penyu sangat sensitif saat bertelur. Pengamatan harus dilakukan dari jarak yang relatif jauh, tidak berisik, dan tidak boleh menyalakan sinar. Waktu yang dibutuhkan oleh seekor penyu dari saat muncul dari laut hingga kembali ke laut berkisar antara 1-11 jam. Waktu tersebut dipengaruhi oleh jenis penyu, tingkat gangguan yang dihadapi penyu, dan kondisi fisik pantai yang bersangkutan. Setelah proses peneluran selesai, pemantau kemudian memindahkan telur-telur tersebut ke area penetasan telur semi alami. Pemindahan tersebut dilakukan untuk menyelamatkan sarang telur dari gelombang air laut, agar telur tidak mengalami pembusukan (Direktorat Konservasi dan Taman Nasional Laut, 2009).

Penelitian ini bertujuan untuk mengidentifikasi aspek-aspek yang perlu diperhatikan dalam mengembangkan kawasan konservasi penyu Pantai Trisik sebagai wadah wisata edukasi di Kulonprogo. Sasaran jangka pendek yang diharapkan adalah untuk mempersiapkan perencanaan destinasi wisata Pantai Trisik, yang dapat dilakukan oleh segenap pemangku kebijakan dan pelaku wisata di Kulonprogo. Sasaran jangka panjang yaitu untuk menjaga kelestarian habitat alami peneluran penyu Pantai Trisik, serta menarik minat pengunjung untuk datang dan turut serta menjaga kelestarian penyu.

Pengembangan daya tarik kawasan konservasi penyu di Pantai Trisik perlu memperhatikan permasalahan yang dihadapi oleh Kelompok Konservasi Penyu Abadi dalam upaya penyelamatan penyu selama ini. Kelompok Konservasi Penyu Abadi terkendala oleh minimnya sarana dan prasarana penangkaran penyu di Pantai TrisikError! Reference source not found.. Kegiatan konservasi yang dilakukan saat ini belum didukung oleh fasilitas penunjang yang memadai, serta belum terdapat sarana terpusat yang dapat digunakan sebagai sumber informasi bagi masyarakat umum dan memaksimalkan potensi rekreasi Pantai Trisik (lihat Gambar 3). Sejauh ini, terdapat 4 bak penampung penyu berukuran masing-masing $1 \times 2$ meter yang tidak dilengkapi saluran penyediaan air asin. Jumlah dan ukuran bak tersebut, tidak sebanding 
dengan jumlah penyu yang mencapai puluhan ekor. Kepadatan di bak penampung tersebut memicu stress pada penyu dan menyebabkan kematian. Selain itu, suplai air untuk habitat penyu selama ini berasal dari air sumur buatan yang berisi air asin resapan. Hal tersebut menyebabkan munculnya jamur di bak-bak penampung penyu, yang kemudian mempengaruhi kesehatan penyu (lihat Gambar 4).

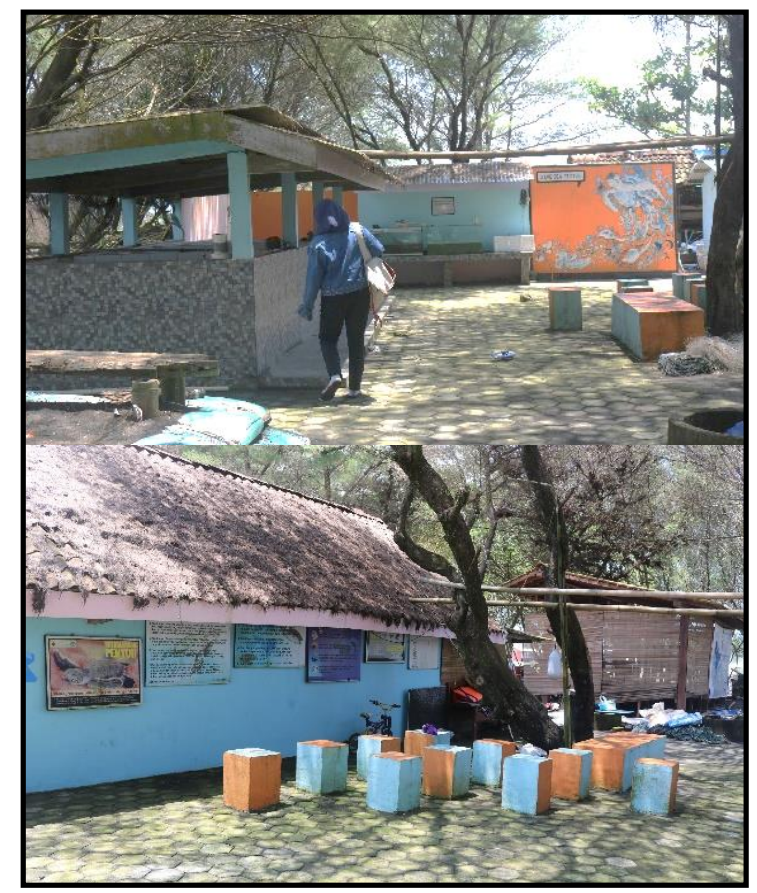

Gambar 3. Kondisi Pusat Konservasi Kelompok Penyu Abadi Pantai Trisik

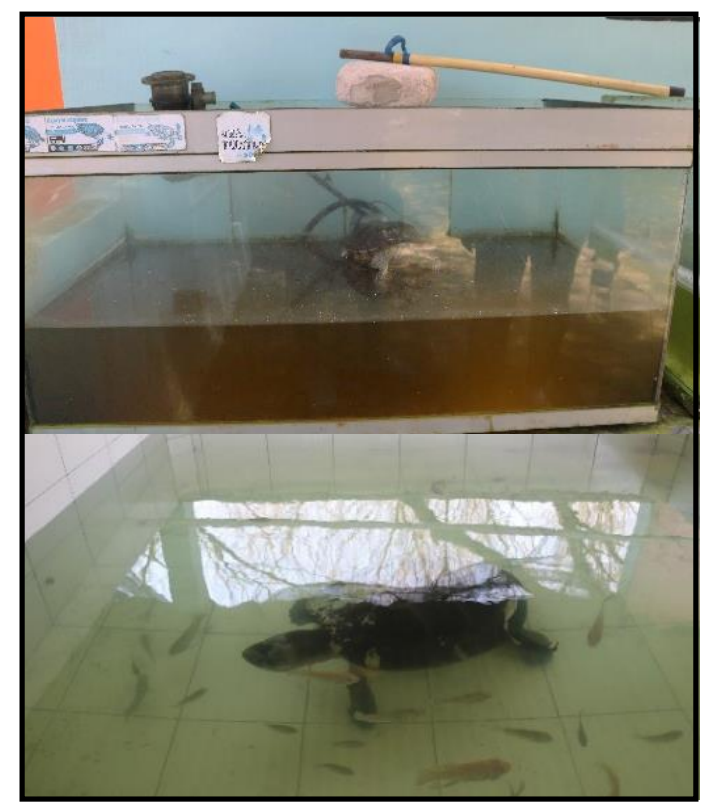

Gambar 4. Kondisi Kolam Penangkaran Penyu di Pusat Konservasi Penyu Abadi Pantai Trisik

Permasalahan dalam penelitian ini yaitu aspek apa saja yang harus dipenuhi untuk mewujudkan wisata edukasi penyu yang rekreatif, tetapi tetap memperhatikan fungsi utamanya sebagai pendukung kegiatan konservasi laut daerah. Dari permasalahan tersebut diambil keputusan bahwa pengembangan daya tarik kawasan konservasi penyu di Pantai Trisik sebagai wisata edukasi, tidak hanya berorientasi pada prinsip desain yang rekreatif, namun juga harus memenuhi persyaratan teknis pengembangan kawasan konservasi laut daerah. Teori yang digunakan dalam penelitian ini yaitu teori prinsip desain rekreatif menurut Suardana dan teori pengembangan kawasan konservasi laut daerah menurut Departemen Kelautan dan Perikanan.

Prinsip desain rekreatif digunakan untuk menghasilkan pengembangan kawasan konservasi penyu Pantai Trisik yang menyenangkan, memiliki daya tarik wisata yang unik, serta memiliki identitas bangunan yang khas. Prinsip desain rekreatif menurut Suardana (2005), terdiri dari:

a. Bentuk dan tampilan bangunan yang dinamis

b. Suasana ruang bebas dan non formal

c. Tidak monoton dalam penggunaan warna dan material

d. Tata bangunan memudahkan sirkulasi pengunjung dalam berwisata

Pemenuhan persyaratan teknis pengembangan kawasan konservasi laut daerah, bertujuan untuk menghasilkan pengembangan kawasan konservasi penyu Pantai Trisik, yang tetap menjaga kelestarian habitat alami penyu Pantai Trisik. Adanya pengembangan kawasan konservasi penyu Pantai Trisik sebagai wisata edukasi tidak boleh mengganggu keseimbangan ekosistem alami Pantai Trisik. Prinsip pengembangan kawasan konservasi laut daerah menurut Departemen Kelautan dan Perikanan (2006), terdiri dari:

a. Prinsip pendekatan ekosistem

Prinsip pendekatan ekosistem berarti desain dan konstruksi kawasan konservasi dikerjakan sesuai dengan struktur, karakteristik, dan dinamika alam Pantai 
Trisik, sebagai habitat alami penyu hijau, penyu sisik, dan penyu lekang. Penjabaran prinsip pendekatan ekosistem antara lain:

1) Menghindari kontak langsung antara area wisata dengan area peneluran alami.

2) Tidak banyak menggunakan lahan agar area vegetasi pantai tetap terjaga.

3) Merespon struktur dan dinamika alam setempat.

4) Harmonisasi bangunan dengan lingkungan setempat.

b. Prinsip keterbukaan

Prinsip keterbukaan berarti kegiatan konservasi meliputi kegiatan pembesaran dan pengembangbiakan satwa liar dengan tetap mempertahankan sifat alaminya. Prinsip keterbukaan kawasan konservasi diterapkan pada pengolahan karakteristik ruang dapat mewadahi kegiatan pengembangbiakan penyu dengan tetap mempertahankan sifat alami penyu di habitat aslinya.

\section{METODE}

Metode penelitian yang digunakan adalah penelitian terapan. Penelitian terapan adalah jenis penelitian yang bertujuan untuk memberikan solusi atas permasalahan tertentu secara praktis. Penelitian ini tidak berfokus pada pengembangan sebuah ide, teori, atau gagasan, tetapi lebih berfokus pada penerapan penelitian tersebut.

Penelitian diawali dengan tahapan perumusan permasalahan dalam melakukan pengembangan kawasan konservasi penyu Pantai Trisik. Tahap berikutnya yaitu pengumpulan data yang terdiri dari data primer dan data sekunder. Data primer terdiri dari data kondisi lapangan yang didapatkan melalui observasi pada tapak di Pantai Trisik, Desa Banaran, Kabupaten Kulonprogo. Data primer yang diperoleh meliputi luasan tapak, batas tapak terhadap kawasan sekitar, serta kondisi iklim dan geografis tapak. Data sekunder adalah data yang diperoleh melalui sumber referensi. Data sekunder yang diperoleh meliputi data tentang kawasan wisata Pantai Trisik, data tentang standar ketersediaan sarana dan prasana konservasi penyu, data tentang standar pengembangan kawasan konservasi laut daerah, serta data tentang pengembangan obyek wisata edukasi. Data yang diperoleh kemudian dianalisis dengan teknik analisis SWOT. Teknik analisis SWOT dipilih karena dianggap mampu melihat persoalan dari empat sisi sekaligus, baik dari sisi positif maupun sisi negatifnya. Keempat sisi tersebut adalah sisi kekuatan (strengths), sisi kelemahan (weakness), sisi peluang (opportunities), dan sisi ancaman (threats). Analisis SWOT dapat digunakan secara ampuh untuk menentukan langkah terbaik penyelesaian masalah Error! Reference source not found.. Analisis data kemudian menghasilkan kriteria perencanaan pengembangan kawasan konservasi. Kriteria yang didapat dari analisa data kemudian disimpulkan dalam bentuk kajian konsep perencanaan pengembangan kawasan konservasi penyu Pantai Trisik sebagai wisata edukasi.

\section{HASIL DAN PEMBAHASAN}

Pantai Trisik merupakan kawasan penyu dewasa dari Samudera Hindia naik ke kawasan pesisir untuk bertelur. Jenis penyu yang bertelur di Pantai Trisik terdiri dari penyu sisik, penyu lekang, dan penyu hijau. Area bertelur alami bagi penyu dewasa berada di rerimbunan vegetasi pandan laut, yang berbatasan langsung dengan tapak. Letak area peneluran alami penyu terhadap area pengembangan dapat dilihat pada Gambar 5 berikut. 


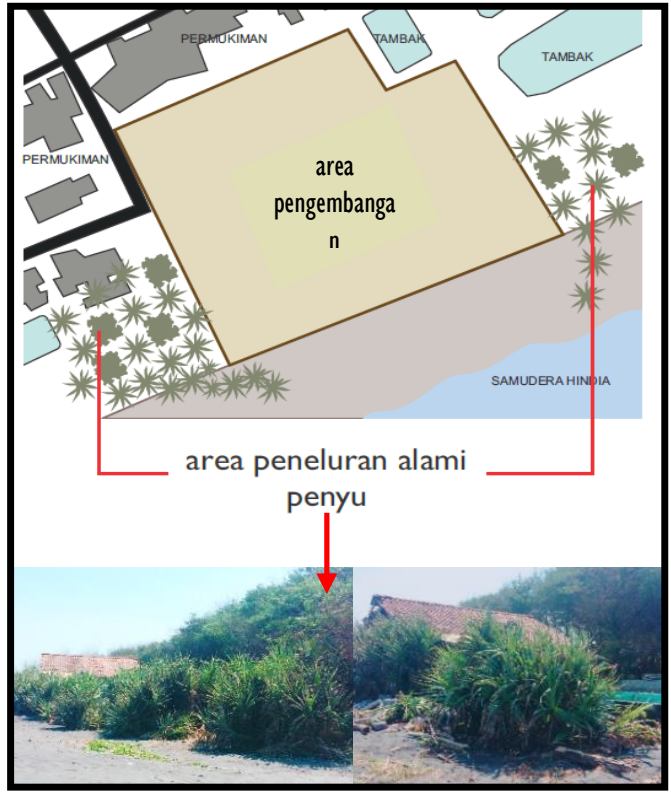

Gambar 5. Area Peneluran Alami Penyu Pantai Trisik

Selain vegetasi pandan laut, pada Pantai Trisik juga terdapat jenis vegetasi lain yang berfungsi merangsang penyu agar naik ke pantai peneluran untuk bertelur. Vegetasi-vegetasi tersebut harus tetap dipertahankan, atau bahkan ditambah, agar kelestarian proses alami peneluran penyu tetap terjaga. Pemetaan vegetasi Pantai Trisik dapat dilihat pada Gambar 6 berikut.

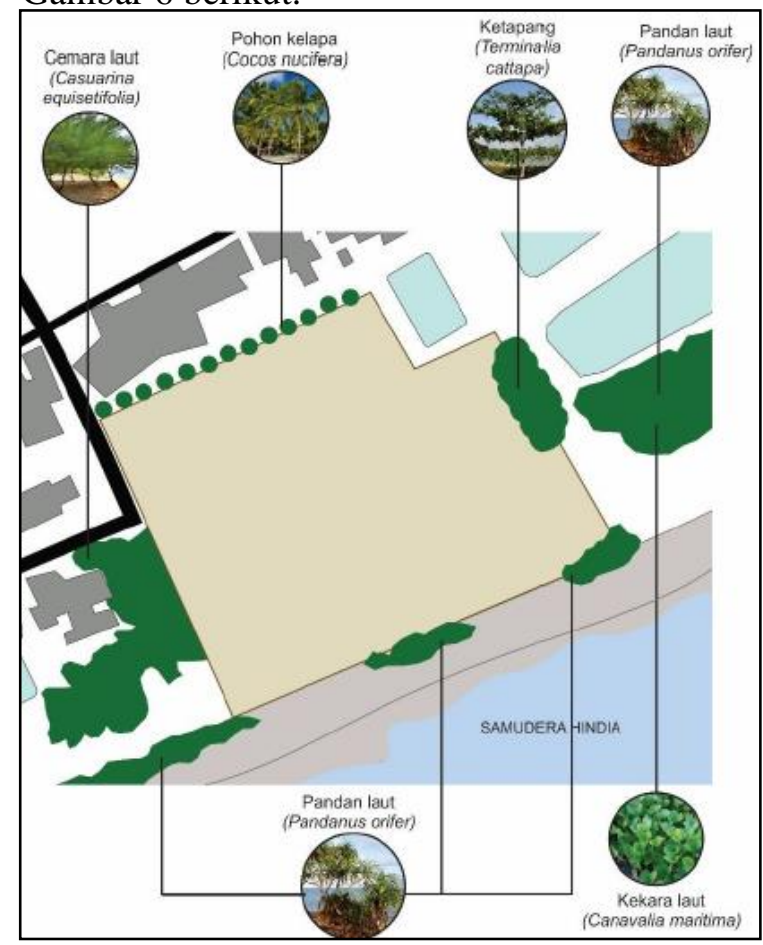

Gambar 6. Vegetasi Eksisting Pesisir Pantai Trisik
Hasil observasi dan penelitian lapangan secara mendalam pada kawasan konservasi penyu Pantai Trisik menyatakan terdapat banyak faktor penting untuk dianalisis. Faktor tersebut terdiri dari faktor positif maupun negatif. Analisis SWOT diandalkan sebagai alat analisis yang mampu menghasilkan solusi dan berbagai strategi penyelesaian masalah di lapangan.

Pada tabel analisis SWOT (Tabel 2), disusun identifikasi faktor dari berbagai kekuatan (strengths), kelemahan (weaknesses), peluang (opportunities), dan ancaman (threats) dari kondisi yang sekarang ada di Pantai Trisik.

Tabel 2. Identifikasi SWOT

\begin{tabular}{|c|c|}
\hline \multirow{4}{*}{$\mathbf{S}$} & STRENGTH - kekuatan (positif) \\
\hline & $\begin{array}{l}\text { Pantai Trisik menjadi habitat alami } \\
\text { peneluran penyu jenis sisik, lekang, dan } \\
\text { hijau }\end{array}$ \\
\hline & $\begin{array}{l}\text { Masyarakat setempat tergabung dalam } \\
\text { Komunitas Penyu Pantai Trisik, turut } \\
\text { berperan aktif dalam kegiatan pelestarian } \\
\text { penyu Pantai Trisik }\end{array}$ \\
\hline & $\begin{array}{l}\text { Dinas Pariwisata Daerah Istimewa } \\
\text { Yogyakarta merencanakan pengembangan } \\
\text { daya tarik kawasan konservasi penyu di } \\
\text { Pantai Trisik sebagai destinasi wisata }\end{array}$ \\
\hline \multirow{5}{*}{$\mathbf{W}$} & WEAKNESS - kelemahan (negatif) \\
\hline & $\begin{array}{l}\text { Kegiatan konservasi yang dilakukan saat } \\
\text { ini belum didukung oleh fasilitas } \\
\text { penunjang yang memadai }\end{array}$ \\
\hline & $\begin{array}{l}\text { Belum terdapat sarana terpusat yang dapat } \\
\text { digunakan sebagai sumber informasi bagi } \\
\text { masyarakat umum dan memaksimalkan } \\
\text { potensi rekreasi Pantai Trisik }\end{array}$ \\
\hline & $\begin{array}{l}\text { Penyediaan air asin dan pengolahan air } \\
\text { kolam penangkaran tidak optimal }\end{array}$ \\
\hline & $\begin{array}{l}\text { Perbandingan ukuran kolam dan jumlah } \\
\text { penyu tidak sesuai standar sehingga } \\
\text { menyebabkan stress pada penyu }\end{array}$ \\
\hline \multirow{4}{*}{$\mathbf{O}$} & OPPORTUNITIES - peluang (positif) \\
\hline & $\begin{array}{l}\text { Peningkatan persentase keberhasilan } \\
\text { menetasnya telur penyu di pusat } \\
\text { konservasi }\end{array}$ \\
\hline & Potensi sumber daya lingkungan \\
\hline & $\begin{array}{l}\text { Program pemerintah menumbuhkan } \\
\text { pengetahuan masyarakat mengenai penyu }\end{array}$ \\
\hline
\end{tabular}




\begin{tabular}{|c|l|}
\hline \multirow{4}{*}{ T } & THREATS - ancaman (negatif) \\
\cline { 2 - 2 } & $\begin{array}{l}\text { Ancaman bencana alam di pesisir pantai } \\
\text { selatan Yogyakarta }\end{array}$ \\
\cline { 2 - 3 } & $\begin{array}{l}\text { Kerusakan habitat alami peneluran penyu } \\
\text { di Pantai Trisik akibat ulah manusia }\end{array}$ \\
\hline
\end{tabular}

Tabel 2 menunjukkan faktor-faktor negatif pada kawasan konservasi penyu Pantai Trisik. Faktor negatif terdiri dari kelemahan (weakness) dan ancaman (threat) di kawasan pengembangan konservasi. Faktor negatif tersebut kemudian menjadi perhatian utama dalam penelitian, untuk dicarikan solusi pemecahan masalahnya. Tabel 2 juga menunjukkan faktor-faktor positif dari kondisi dan situasi sosial, serta alam lingkungan kawasan konservasi penyu Pantai Trisik. Faktor-faktor positif tersebut berupa kekuatan (strength) dan peluang (opportunities) yang terdapat pada masyarakat lokal dan lingkungan setempat. Penggalian dan elaborasi faktorfaktor positif diharapkan dapat menjadi strategi pengolahan kawasan konservasi menjadi sebuah destinasi wisata edukasi yang tetap memperhatikan kelestarian habitat alami penyu Pantai Trisik.

Tabel 3 berupa kajian analisis SWOT untuk mencari solusi dari faktor-faktor negatif, dan merumuskan jenis pemanfaatan dari faktorfaktor positif kawasan pengembangan konservasi penyu Pantai Trisik. Faktor-faktor positif dapat menjadi sebuah strategi untuk menyusun dan mengembangkan gagasan untuk memperbaiki faktor-faktor negatif di kawasan Pantai Trisik.

Tabel 3. Analisis SWOT

\begin{tabular}{|l|l|l|}
\hline & OPPORTUNITIES & \multicolumn{1}{c|}{ THREATS } \\
\hline & [a] Perencanaan & [b] Pengembangan \\
& wadah kegiatan & kawasan konservasi \\
& pemeliharaan penyu & penyu Pantai Trisik \\
$\mathbf{S}$ & Komunitas Penyu & menjadi suatu \\
$\mathbf{T}$ & Abadi Pantai Trisik & wadah wisata \\
$\mathbf{R}$ & yang juga berfungsi & edukasi dengan \\
$\mathbf{E}$ & sebagai wadah & tetap menjaga \\
$\mathbf{N}$ & wisata edukasi bagi & kelestarian alami \\
$\mathbf{G}$ & masyarakat umum & habitat peneluran \\
$\mathbf{T}$ & & penyu Pantai Trisik \\
\cline { 3 - 3 } $\mathbf{H}$ & & [c] Pengembangan \\
$\mathbf{S}$ & & kawasan konservasi \\
& & penyu Pantai Trisik \\
& & menjadi wadah \\
& & wisata edukasi \\
\hline
\end{tabular}

\begin{tabular}{|l|l|l|}
\hline & & $\begin{array}{l}\text { dengan } \\
\text { memperhatikan } \\
\text { aspek resiliensi } \\
\text { bangunan terhadap } \\
\text { bencana alam }\end{array}$ \\
\hline & [d] Perencanaan & {$[$ e] Konsep } \\
W & wadah kegiatan & pengembangan \\
$\mathbf{E}$ & pemeliharaan dan & kawasan konservasi \\
$\mathbf{A}$ & wisata edukasi & penyu Pantai Trisik \\
$\mathbf{K}$ & penyu Pantai Trisik & untuk \\
$\mathbf{N}$ & dengan memenuhi & menghilangkan \\
$\mathbf{E}$ & standar pedoman & semua \\
$\mathbf{S}$ & teknis pengelolaan & masalah/konflik di \\
$\mathbf{S}$ & konservasi penyu & Pantai Trisik. \\
$\mathbf{E}$ & menurut Direktorat & \\
$\mathbf{S}$ & Konservasi dan & \\
& Taman Nasional & \\
\hline
\end{tabular}

Analisis pertama yaitu dengan mempertimbangkan faktor positif di kawasan pengembangan kawasan konservasi penyu Pantai Trisik, yaitu kekuatan (strengths) dan peluang (opportunities). Kedua faktor dikaji untuk menemukan kebijakan utama arah perencanaan pengembangan kawasan wisata. Penelitian menyimpulkan bahwa arah pengembangan yaitu berupa wadah kegiatan pemeliharaan penyu yang dilakukan oleh Komunitas Penyu Abadi Pantai Trisik, serta wadah wisata edukasi yang diperuntukkan bagi masyarakat umum (Tabel 3 butir a). Sebagai wadah wisata edukasi, pengembangan kawasan konservasi penyu Pantai Trisik perlu memperhatikan aspek estetika dan keunikan dari obyek yang disampaikan dan dipamerkan. Dalam ranah perancangan obyek arsitektur, hal tersebut merujuk pada pengolahan massa dan tampilan bangunan. Menurut Suardana (2005), suatu obyek wisata harus memiliki olah massa bangunan dan tampilan bangunan yang dinamis, serta tidak monoton dalam penggunaan warna dan material. Olah bentuk yang dinamis tersebut harus dapat menunjukkan identitas fungsi bangunan, yaitu sebagai bangunan wisata penyu agar memberikan kesan kepada wisatawan. Aspek estetika sebagai bangunan wisata juga perlu diimbangi dengan fungsi bangunan sebagai wadah pemeliharaan penyu di pesisir Pantai Trisik. Menurut Departemen Kelautan dan Perikanan (2006), olah bentuk bangunan pesisir pantai harus dapat merespon struktur dan dinamika alam setempat. Selain itu, untuk 
pengolahan tampilan bangunannya harus memiliki harmonisasi dengan lingkungan sekitar (Departemen Kelautan dan Perikanan, 2006), yang dalam hal ini yaitu pesisir Pantai Trisik.

Analisis kedua yaitu dengan mempertimbangkan potensi faktor kekuatan (strengths) untuk menyusun strategi mengurangi faktor ancaman (threats) pada kawasan konservasi penyu Pantai Trisik. Analisis memberikan hasil bahwa diperlukannya pengembangan kawasan konservasi penyu Pantai Trisik menjadi suatu wadah wisata edukasi, dengan tetap menjaga kelestarian alami habitat peneluran penyu Pantai Trisik (Tabel 3 butir b). Dalam ranah perancangan obyek arsitektur, hal tersebut merujuk pada pengolahan tapak. Olah tapak pengembangan kawasan konservasi laut perlu menghindari kontak langsung antara area wisata dengan area peneluran alami, dan penyediaan minimal $60 \%$ lahan vegetasi (Departemen Kelautan dan Perikanan, 2006). Lebih lanjut, menurut Departemen Kelautan dan Perikanan (2006), penghindaran kontak langsung antara area wisata dengan area peneluran alami, salah satunya dilakukan dengan pengaturan ketinggian bangunan agar tidak tertangkap sudut pandang penyu sebesar 15 derajat (lihat Gambar 6). Adapun jenis vegetasi yang diperlukan yaitu vegetasi perangsang penyu bertelur ke pantai, yaitu pandan laut, cemara laut, dan ketapang.

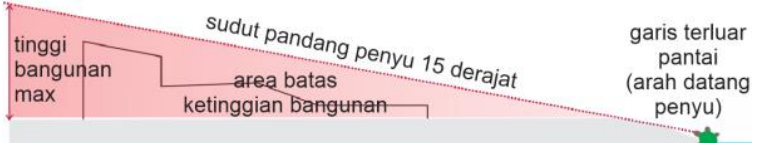

Gambar 6. Pengaturan Ketinggian Bangunan Sumber: Direktorat Konservasi dan Taman Nasional Laut, 2009, diolah

Hasil berikutnya yaitu pengembangan kawasan konservasi penyu Pantai Trisik menjadi wadah wisata edukasi dengan memperhatikan aspek resiliensi bangunan terhadap bencana alam (Tabel 3 butir c). Wilayah kepesisiran Pantai Trisik rentan terhadap bencana gempa bumi dan tsunamiError! Reference source not found.. Resiliensi bangunan terhadap bencana alam tersebut merujuk pada pengolahan bentuk massa bangunan agar dirancang dengan merespon struktur dan dinamika alam setempat
(Departemen Kelautan dan Perikanan, 2006). Bentuk-bentuk yang dipilih yaitu bentuk yang memiliki kekuatan menahan gaya aksial yang baik, salah satunya yaitu segi empat.

Analisis ketiga yaitu kajian faktor negatif kelemahan (weakness) dengan mengelaborasikan faktor positif peluang (opportunities). Analisis memberikan hasil bahwa perencanaan wadah kegiatan pemeliharaan dan wisata edukasi penyu Pantai Trisik, dilakukan dengan memenuhi standar pedoman teknis pengelolaan konservasi penyu menurut Direktorat Konservasi dan Taman Nasional Laut (Tabel 3 butir d). Dalam ranah perancangan obyek arsitektur, hal tersebut merujuk pada pengolahan ruang. Sebagai wadah wisata edukasi penyu, ruang-ruang dirancang memiliki suasana yang bebas dan nonformalError! Reference source not found.. Sebagai wadah kegiatan pemeliharaan penyu, ruang-ruang harus diolah dengan spesifikasi karakteristik ruang yang mewadahi kegiatan pengembangbiakan penyu dengan tetap mempertahankan sifat alami masingmasing jenis penyu di habitat aslinya (Departemen Kelautan dan Perikanan, 2006). Hal tersebut diwujudkan dengan pemenuhan standar spesifikasi kolam penangkaran berdasar Pedoman Teknis Konservasi Penyu (Direktorat Konservasi dan Taman Nasional Laut, 2009). Pengadaan karakteristik habitat penyu pada pengembangan kawasan konservasi penyu Pantai Trisik dapat dilihat pada Tabel 4 berikut.

Tabel 4. Pengadaan Karakteristik Habitat Penyu pada Kolam Penangkaran

\begin{tabular}{|c|c|c|}
\hline \multicolumn{3}{|c|}{ Spesifikasi Kolam Penangkaran } \\
\hline $\begin{array}{l}\text { Standar } \\
\text { Luasan }\end{array}$ & $\begin{array}{c}\text { Bentuk Visual } \\
\text { Air }\end{array}$ & Elemen Lansekap \\
\hline \multicolumn{3}{|c|}{ Kolam Penetasan Telur Semi Alami } \\
\hline $\begin{array}{l}2 \mathrm{~m}^{2} / \\
\text { lubang }\end{array}$ & $\begin{array}{l}\text { Kolam berarus } \\
\text { dengan } \\
\text { kedalaman 20- } \\
30 \mathrm{~cm} \text {, untuk } \\
\text { merangsang } \\
\text { tukik yang } \\
\text { sudah menetas } \\
\text { untuk bergerak } \\
\text { ke kolam tukik }\end{array}$ & $\begin{array}{l}\text { a. Pasir pantai } \\
\text { sebagai media } \\
\text { penetasan telur. } \\
\text { b. Vegetasi } \\
\text { pandan laut } \\
\text { yang } \\
\text { merupakan } \\
\text { tanaman tempat } \\
\text { induk penyu } \\
\text { menaruh telur } \\
\text { di habitat } \\
\text { aslinya. }\end{array}$ \\
\hline
\end{tabular}




\begin{tabular}{|c|c|c|}
\hline \multicolumn{3}{|c|}{ Kolam Tukik } \\
\hline $\begin{array}{l}0,5 \mathrm{~m}^{2} / \\
\text { tukik }\end{array}$ & $\begin{array}{l}\text { Kolam berarus } \\
\text { dengan } \\
\text { kedalaman 20- } \\
30 \mathrm{~cm} \text {, sebagai } \\
\text { wadah tukik } \\
\text { belajar } \\
\text { berenang }\end{array}$ & $\begin{array}{l}\text { Padang lamun } \\
\text { pada dasar kolam } \\
\text { sebagai makanan } \\
\text { tukik. }\end{array}$ \\
\hline \multicolumn{3}{|c|}{ Kolam Penyu Sisik Dewasa } \\
\hline $\begin{array}{l}4 \mathrm{~m}^{2} / \\
\text { penyu } \\
\text { remaja } \\
15 \mathrm{~m}^{2} / \\
\text { penyu } \\
\text { dewasa }\end{array}$ & $\begin{array}{l}\text { Kolam tidak } \\
\text { berarus dengan } \\
\text { kedalaman } \\
\text { minimal } 3 \\
\text { meter dengan } \\
\text { elemen } \\
\text { pembatas untuk } \\
\text { membatasi } \\
\text { interaksi } \\
\text { pengunjung }\end{array}$ & $\begin{array}{l}\text { Terumbu karang } \\
\text { dan rumput laut } \\
\text { sebagai makanan } \\
\text { penyu sisik. }\end{array}$ \\
\hline \multicolumn{3}{|c|}{ Kolam Penyu Lekang Dewasa } \\
\hline $\begin{array}{l}4 \mathrm{~m}^{2} / \\
\text { penyu } \\
\text { remaja } \\
15 \mathrm{~m}^{2} / \\
\text { penyu } \\
\text { dewasa }\end{array}$ & $\begin{array}{l}\text { Kolam tidak } \\
\text { berarus dengan } \\
\text { kedalaman } \\
\text { minimal } 3 \\
\text { meter dengan } \\
\text { elemen } \\
\text { pembatas untuk } \\
\text { membatasi } \\
\text { interaksi } \\
\text { pengunjung }\end{array}$ & $\begin{array}{l}\text { Ikan-ikan kecil } \\
\text { sebagai makanan } \\
\text { penyu lekang } \\
\text { beserta terumbu } \\
\text { karang. }\end{array}$ \\
\hline \multicolumn{3}{|c|}{ Kolam Penyu Hijau Dewasa } \\
\hline $\begin{array}{l}4 \mathrm{~m}^{2} / \\
\text { penyu } \\
\text { remaja } \\
15 \mathrm{~m}^{2} / \\
\text { penyu } \\
\text { dewasa }\end{array}$ & $\begin{array}{l}\text { Kolam berarus } \\
\text { dengan } \\
\text { kedalaman } 3 \\
\text { meter. Untuk } \\
\text { kolam yang } \\
\text { berfungsi } \\
\text { sebagai kolam } \\
\text { interaksi, } \\
\text { diperbolehkan } \\
\text { membuat } \\
\text { kolam dengan } \\
\text { kedalaman } 50 \\
\text { cm, yang berisi } \\
\text { penyu remaja. }\end{array}$ & $\begin{array}{l}\text { Padang lamun } \\
\text { pada dasar kolam } \\
\text { sebagai makanan } \\
\text { penyu hijau. }\end{array}$ \\
\hline
\end{tabular}

Sumber: Direktorat Konservasi dan Taman Nasional Laut, 2009 (diolah)

Analisis keempat yaitu dengan mempertimbangkan kedua faktor negatif di kawasan penelitian, yaitu faktor kelemahan (weaknesses) dan faktor ancaman (threats). Elaborasi dari kedua faktor negatif tersebut dengan mempertimbangkan faktor positif di kawasan menghasilkan sebuah resume analisis konsep sistem perencanaan terpadu (Tabel 3 butir e). Perencanaan pengembangan kawasan konservasi penyu Pantai Trisik secara keseluruhan menggunakan prinsip desain rekreatif dan prinsip pengembangan kawasan konservasi laut daerah. Konsep ini disimpulkan menjadi sebuah konsep yang paling tepat untuk mengurangi semua potensi konflik yang ada di kawasan pengembangan konservasi penyu Pantai Trisik.

\section{KESIMPULAN}

Penelitian ini menyimpulkan beberapa hal pokok yang dapat diimplementasikan pada pengembangan kawasan konservasi penyu Pantai Trisik, untuk menjadi dasar perencanaan pembangunan di masa depan. Prinsip desain rekreatif dengan tetap mempertimbangkan pedoman teknis pengembangan kawasan konservasi laut menjadi strategi utama perencanaan pengembangan kawasan konservasi penyu Pantai Trisik. Kesinambungan dari kedua teori tersebut dapat mewujudkan wisata edukasi penyu yang rekreatif, tetapi tetap memperhatikan fungsi utama sebagai pendukung kegiatan konservasi laut daerah, sehingga tidak merusak habitat alami di Pantai Trisik. Prinsip desain rekreatif dan prinsip pengembangan kawasan konservasi laut daerah diaplikasikan untuk mengolah ruang, tapak, serta bentuk dan tampilan menyesuaikan kebutuhan kegiatan.

Olah tapak pada pengembangan kawasan konservasi penyu Pantai Trisik dibuat agar menghindari kontak langsung antara area wisata dengan area peneluran alami, serta tersedia $60 \%$ lahan untuk area vegetasi dengan jenis vegetasi yang banyak tumbuh di Pantai Trisik.

Olah ruang pada pengembangan kawasan konservasi penyu Pantai Trisik dibuat agar memiliki suasana yang bebas dan nonformal serta dapat mewadahi kegiatan pengembangbiakan penyu dengan tetap mempertahankan sifat alaminya, melalui pengadaan elemen air dan lansekap di dalam massa bangunan pemeliharaan penyu.

Olah bentuk pada pengembangan kawasan konservasi penyu Pantai Trisik dibuat dinamis dan merespon struktur dan dinamika alam setempat, melalui olah bentuk yang 
menunjukkan identitas bangunan sebagai bangunan wisata penyu dan memiliki kekuatan dalam menahan gaya aksial tapak Pantai Trisik.

Olah tampilan pada pengembangan kawasan konservasi penyu Pantai Trisik dibuat agar memiliki permainan warna dan tekstur dan harmonis dengan lingkungan, melalui pemilihan material bangunan.

\section{REFERENSI}

Error! No bookmark name given. 